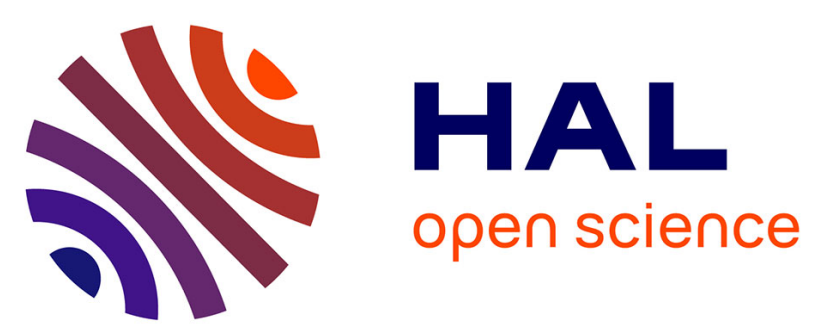

\title{
Diversity of free-living amoebae in soils and their associated human opportunistic bacteria
}

Elodie Denet, Bénédicte Coupat-Goutaland, Sylvie Nazaret, Michel Pélandakis, Sabine Favre-Bonté

\section{- To cite this version:}

Elodie Denet, Bénédicte Coupat-Goutaland, Sylvie Nazaret, Michel Pélandakis, Sabine Favre-Bonté. Diversity of free-living amoebae in soils and their associated human opportunistic bacteria. Parasitology Research, 2017, 116 (11), pp.3151-3162. 10.1007/s00436-017-5632-6 . hal-02335511

\section{HAL Id: hal-02335511 \\ https://hal.science/hal-02335511}

Submitted on 29 Oct 2019

HAL is a multi-disciplinary open access archive for the deposit and dissemination of scientific research documents, whether they are published or not. The documents may come from teaching and research institutions in France or abroad, or from public or private research centers.
L'archive ouverte pluridisciplinaire HAL, est destinée au dépôt et à la diffusion de documents scientifiques de niveau recherche, publiés ou non, émanant des établissements d'enseignement et de recherche français ou étrangers, des laboratoires publics ou privés. 


\title{
Diversity of free-living amoebae in soils and their associated human opportunistic bacteria
}

\author{
Elodie Denet $^{1,2}$ (1) $\cdot$ Bénédicte Coupat-Goutaland ${ }^{2,3} \cdot$ Sylvie Nazaret $^{1} \cdot$ \\ Michel Pélandakis $^{2} \cdot$ Sabine Favre-Bonté ${ }^{1}$
}

Received: 17 July 2017 / Accepted: 21 September 2017 / Published online: 7 October 2017

(C) Springer-Verlag GmbH Germany 2017

\begin{abstract}
Free-living amoebae (FLA) are ubiquitous protozoa found worldwide in the environment. They feed by phagocytosis on various microorganisms. However, some bacteria, i.e., amoebae-resistant bacteria (ARB) or bacterial endocytobionts, can resist phagocytosis and even multiply inside FLA. This study investigated the diversity of culturable FLA in various soils from agricultural and mining sites and their bacterial endocytobionts. FLA were cultured on nonnutrient agar with alive Escherichia coli and identified by PCR and sequencing. Amoebae were lysed and bacterial endocytobionts were cultured on TSA $1 / 10$ and Drigalski medium. Bacterial isolates were identified by PCR and $16 \mathrm{~S}$ rDNA sequencing and characterized for their antibiotic resistance properties. To measure bacterial virulence, the amoebal model Dictyostelium discoideum was used. The analysis of FLA diversity showed that Tetramitus was the most prevalent genus in agricultural soil from Burkina Faso (73\%) and garden soil from Vietnam (42\%) while Naegleria and Acanthamoeba were dominant genera in mining soil from Vietnam $(55 \%)$ and
\end{abstract}

Electronic supplementary material The online version of this article (https://doi.org/10.1007/s00436-017-5632-6) contains supplementary material, which is available to authorized users.

Elodie Denet

elodie.denet@live.fr

1 Université Lyon 1, CNRS UMR 5557/ UMR INRA 1418 Ecologie Microbienne, F-69622 Villeurbanne CEDEX, France

2 Université Lyon 1, CNRS UMR 5240 Microbiologie, Adaptation, Pathogénie, F-69622 Villeurbanne CEDEX, France

3 Present address: CIRI, Centre International de Recherche en Infectiologie, Team HoriGene, Inserm, U1111, Université Claude Bernard Lyon 1, CNRS, UMR5308, École Normale Supérieure de Lyon, 69100 Villeurbanne, France
French alpine soil (77\%). Some genera were only present in one out of the four soils analyzed. The bacterial endocytobiont included Firmicutes, Bacteroidetes, Proteobacteria, and Actinobacteria. Human opportunistic pathogens identified as Pseudomonas aeruginosa, Stenotrophomonas maltophilia, and Burkholderia cepacia were found associated with amoebae including Micriamoeba, Tetramitus, Willaertia, or Acanthamoeba. Some of these bacteria showed various antibiotic resistance phenotypes and were virulent. Our study confirms that the occurrence of these opportunistic bacteria with FLA in soils may be important for the survival, multiplication, and spread of pathogens in the environment.

Keywords Free-living amoebae $\cdot$ Soil $\cdot$ Bacterial endocytobiont $\cdot$ Human pathogen $\cdot$ Antibiotic resistance . Virulence

\section{Introduction}

Free-living amoebae (FLA) are ubiquitous protozoa that can be isolated from a wide range of sources around the world including water, sediment, soil, compost, and air. They occur in natural and engineered aquatic environments such as rivers (Pagnier et al. 2015), water biofilms (Amissah et al. 2014), tap water (Delafont et al. 2013), hospital water networks (Thomas et al. 2006), cooling towers (Atlan et al. 2012), water pipes, and wastewater treatment plants (Hoffmann and Michel 2001; Schulz et al. 2015). Their abundance was reported to be higher in wastewater as these environments are enriched in organic material and bacteria, which serve as food for protozoa (Ramirez et al. 2005, 2014). Some studies on the prevalence and diversity of FLA in soils have been conducted; however, they focus on extreme environments such as desert soils (Rodríguez-Zaragoza and Garcia 1997; Rodriguez Zaragoza 
et al. 2005) and wet soils from the Arctic and Antarctic (Tyml et al. 2016). Acanthamoeba (Geisen et al. 2014), Vermamoeba (formerly Hartmannella) (Mohaghegh et al. 2016) and Naegleria (Tyml et al. 2016) are among the most frequently described soil amoebal genera identified using culture-based approaches.

FLA belong to three groups among the eukaryotic tree of life: Amoebozoa, Excavata, and Opisthokonta. They exist in two different forms: the cyst, which is a dormant stage, and the trophozoite, which is the reproductive and active feeding stage. An additional flagellate form has been described in Naegleria (Greub and Raoult 2004). In the environment, FLA feed by phagocytosis on various microorganisms including algae, fungi, and bacteria, and therefore play a primordial role in microbial communities (Rodríguez-Zaragoza 1994). Even if this predation exists, co-culture approaches (Evstigneeva et al. 2009) and, more recently, metagenomics approaches (Garcia-Sanchez et al. 2013; Delafont et al. 2013) showed that a wide range of bacterial species is resistant to phagocytosis. These bacteria were named ARB for "amoebaeresistant bacteria" (Greub and Raoult 2004) or bacterial endocytobionts (Scheid 2014; Balczun and Scheid 2017). Among them, there are obligate or facultative intracellular bacteria such as Chlamydia-related bacteria (Schmitz-Esser et al. 2008), but also various species known as human pathogens such as Legionella pneumophila, Streptococcus pneumoniae, Bacillus cereus, Staphylococcus aureus, or Mycobacterium avium (Cirillo et al. 1997; Huws et al. 2008; Evstigneeva et al. 2009; Scheikl et al. 2014). It was recently shown that the bacterial community associated with FLA present in drinking water networks was dominated by Proteobacteria, namely Pseudomonas and Stenotrophomonas genera (Delafont et al. 2016). Despite being less prevalent than Legionella spp. or Mycobacterium spp., Pseudomonas aeruginosa was frequently detected among various waterborne opportunistic pathogens associated to Vermamoeba vermiformis and Acanthamoeba spp. in a drinking water distribution system (Lu et al. 2016). Several studies showed that some bacteria not only resist phagocytosis but also survive and multiply and might exhibit enhanced virulence and antibacterial resistance after growth in amoebae (Loret and Greub 2010). Therefore, the role of FLA as vectors and reservoirs of human pathogens is of particular concern.

Most studies investigating the prevalence of intra-amoebal bacteria were conducted on water habitats. To our knowledge, only one study characterized the diversity of ARB with FLA in soils using co-culture approaches (Evstigneeva et al. 2009). However, soils represent an important reservoir of antibioticresistant bacteria and antibiotic-resistant genes (Canteón 2009). Similarly, opportunistic human pathogens are present in soil either as indigenous and biologically active and/or transient populations suggesting that soil FLA can also be reservoirs of resistant human pathogens (Greub and Raoult 2004).
In this context, the aim of our study was (i) to evaluate the prevalence and diversity of amoebae from several soils chosen for their various use (agricultural and mining sites) and geographical origins, i.e., France, Burkina Faso, and Vietnam, and (ii) to determine the diversity of bacterial endocytobionts and their antibiotic resistance and virulence properties. As we were interested in analyzing the bacterial endocytobiont per amoebal genera and in antibiotic resistance as well as virulence properties per bacterial species, our study was conducted using a cultured-based approach.

\section{Materials and methods}

\section{Soil origin and sampling}

Studied soils were from France, Vietnam, and Burkina Faso. They were chosen to represent various geographical origins, climates, and vegetation covers. Samples from France were collected in an alpine pasture (Le Sapey, Rhône-Alpes region, continental climate) during spring in May. Samples from Vietnam were collected in a garden at the University of Hanoï (V1) and at the Trai Cau mining site, Thai Nguyen province (V2), during winter (March) under tropical climate. Those from Burkina Faso were collected in a field planted with sorghum at the periphery of Ouagadougou during summer (February after a rainy period) under sub-Sahelian climate. At each location, the samples were collected from the upper layer (0-10 or 0-20 cm) and sifted through 2-mm-mesh sieves before processing (Deredjian et al. 2016). Soil characteristics are shown in Supplementary Table 1.

\section{Isolation of free-living amoebae}

Free-living amoebae were extracted according to Rodriguez Zaragoza et al. 2005 and Stefan et al. 2014 with the following modifications: $5 \mathrm{~g}$ of fresh soil was mixed with $5 \mathrm{ml}$ of a Neff's saline solution for 3 min using a vortex. The homogeneous soil suspension was left to settle for $5 \mathrm{~min}$ and was serially diluted 10-fold in a Neff's saline solution, and $1 \mathrm{ml}$ of each dilution was spread on 10 non-nutrient agar plates seeded with a thin layer of alive Escherichia coli K12 (NNA-E. coli) and incubated at $30^{\circ} \mathrm{C}$ for 7 days. The plates were daily monitored with an inverted phase contrast microscope (Nikon biostation IM with a single $\times 40$ lens) at $\times 400$ magnification to search for the amoebal emerging fronts. The amoebal emerging fronts were then isolated and subcultured on fresh NNA-E. coli until obtaining pure culture (Jacquier et al. 2013). These fronts were first examined phenotypically for the size of the trophozoite forms and the size and characteristics of the cysts. For each soil sample, the concentration of amoebae was determined following the most probable number (MPN) method with $95 \%$ of interval confidence (De Man 
1975). Then, amoebae were recovered by scraping the agar plate with a loop for collection, DNA extraction, or lysis.

\section{Identification of free-living amoebae}

\section{Principle}

DNA from amoebae was obtained by cell lysis using the freeze-thaw method $\left(100{ }^{\circ} \mathrm{C}\right.$ for $15 \mathrm{~min}$ before transfer at $-20^{\circ} \mathrm{C}$ ). The identification was confirmed by ITS-PCR analyses derived from Pelandakis and Pernin (2002) with more conserved primers (namely $\mathrm{C} 1$ ) in order to detect most soil amoebae. The upper primer $(\mathrm{C} 1 \mathrm{U})$ and the reverse primer $(\mathrm{C} 1 \mathrm{R})$ were located in the small-subunit (SSU) and the large-subunit (LSU) rRNA genes, respectively. This procedure together with the morphological analysis enabled us to identify most soil amoebal genera (whose most frequently encountered genera were Vermamoeba, Naegleria, and the closely related genera). The SSU-PCR analyses according to Atlan et al. (2012) were used to confirm the identity of several isolates and if negative ITS-PCR results were observed. Additionally, Acanthamoeba being sometimes difficult to amplify with the ITS-PCR method because of a particularly longlength ITS region $(1.3 \mathrm{~kb})$, we used the genus-specific PCR for Acanthamoeba using the JDP primers (Schroeder et al. 2001) to assess the identity of the genus.

\section{PCR procedure}

The ITS-PCR were performed using the upper primer $\mathrm{C} 1$ (C1U: 5' TACGTCCCTGCCTTTTGT 3'), and the reverse primer C1 (C1R: 5' TATGCTTAAATYCAGSGGGT 3'). PCR was conducted in a final reaction volume of $38 \mu \mathrm{L}$ containing $3 \mu \mathrm{L}$ template, $19 \mu \mathrm{L}$ of EconoTaq PLUS GREEN Master Mix (Euromedex, Souffelweyersheim, France), with forward and reverse primers $2.5 \mu \mathrm{L}(10 \mu \mathrm{M})$ each. Amplification conditions were $3 \mathrm{~min}$ pre-heating at $95{ }^{\circ} \mathrm{C}$, followed by 35 cycles at $95{ }^{\circ} \mathrm{C}$ for $30 \mathrm{~s}, 56{ }^{\circ} \mathrm{C}$ for $30 \mathrm{~s}$, $72{ }^{\circ} \mathrm{C}$ for $1 \mathrm{~min}$, and final extension for $5 \mathrm{~min}$ at $72^{\circ} \mathrm{C}$. The SSU-rDNA PCR was performed according to Atlan et al. 2012 which amplifies approximately $700 \mathrm{bp}$ of the $18 \mathrm{~S}$ rRNA gene. PCR analyses were performed using a CFX96 real-time thermocycler (Bio-Rad, Marnes-la-Coquette, France).

The specific PCR for Acanthamoeba was carried out using the specific primers JDP1 (5'GGCCCAGATCGTTT ACCGTGAA 3') and JDP2 (5' TCTCACAAGCTGCT AGGGGAGTCA $3^{\prime}$ ) which amplify approximately $500 \mathrm{bp}$ of the 18S rRNA gene (Schroeder et al. 2001). Amplification was conducted in a final reaction volume of $38 \mu \mathrm{L}$ containing $3 \mu \mathrm{L}$ template, $19 \mu \mathrm{L}$ of EconoTaq PLUS GREEN Master Mix, with forward and reverse primers $2.5 \mu \mathrm{L}$ $(10 \mu \mathrm{M})$ each. Amplification conditions were 3 min pre- heating at $94{ }^{\circ} \mathrm{C}$, followed by 30 cycles at $94{ }^{\circ} \mathrm{C}$ for $30 \mathrm{~s}$, $58{ }^{\circ} \mathrm{C}$ for $30 \mathrm{~s}, 72{ }^{\circ} \mathrm{C}$ for $30 \mathrm{~s}$, and final extension for $3 \mathrm{~min}$ at $72{ }^{\circ} \mathrm{C}$ (Bio-Rad).

Amplified DNA was detected by $1.5 \%$ agarose gel electrophoresis and visualized by ethidium bromide staining. Amplicons were submitted for purification and sequencing by GENOSCREEN (Lille, France) using ABI3730XL. Nucleotide sequences were about $700 \mathrm{bp}$ and were identified by a BLAST search optimized for highly similar sequences (NCBI megablast algorithm).

\section{Isolation of bacterial endocytobionts}

Amoebal lysis was performed from the pure subculture of amoebae showing different morphological features of trophozoite and cysts. Amoebae were harvested by cell-scraping and suspended in $1 \mathrm{~mL}$ of Neff's medium. After two wash steps, amoebal lysis was performed by shearing for $5 \mathrm{~min}$ with a $26 \mathrm{G}$ needle. Bacterial endocytobionts were enumerated by performing a 10 -fold dilution of the lysate from $10^{0}$ to $10^{-4}$ and $100 \mu \mathrm{l}$ of each dilution was spread on non-selective TSA 1/10 medium (Oxoïd) and on Drigalski selective medium (Biokar diagnostics) to detect gram-negative species including various opportunistic pathogens. Three plates were inoculated per dilution. The plates were incubated at $30{ }^{\circ} \mathrm{C}$ for 4 days. Macroscopic characteristics of the growing colonies were regularly monitored and each isolate was subcultured on TSA 1/ 10 or Drigalski for further analysis. Bacterial endocytobionts were isolated by a culture approach and a representative of each morphotype of bacteria was used for the sequencing.

\section{Identification of bacterial endocytobionts}

A representative of each morphotype on TSA $1 / 10$ and Drigalski media was selected for sequencing. DNA from bacterial endocytobiont was obtained by lysing cells using the freeze-thaw method. The PCR analyses were performed using universal primers 8F (5' AGAGTTTGATCCTGGCTCAG 3') and 1492R (5' AAGGAGGTGATCCAGCCGCA 3') targeting 16S rDNA gene (Weisburg et al. 1991). PCR was conducted in a final reaction volume of $25 \mu \mathrm{L}$ containing $2 \mu \mathrm{L}$ of a bacterial cell lysate as a source of DNA template, $0.25 \mu \mathrm{L}$ TaqCore, $2.5 \mu \mathrm{L}$ dNTP $(2 \mathrm{mM}), 2.5 \mu \mathrm{L}$ of PCR buffer $10 \times$ with $\mathrm{MgCl}_{2}$, with forward and reverse primers $1.25 \mu \mathrm{L}$ $(10 \mu \mathrm{M})$ each. Amplification conditions were: $5 \mathrm{~min}$ preheating at $94{ }^{\circ} \mathrm{C}$, followed by 30 cycles at $94{ }^{\circ} \mathrm{C}$ for $1 \mathrm{~min}$, $60{ }^{\circ} \mathrm{C}$ for $1 \mathrm{~min}, 72{ }^{\circ} \mathrm{C}$ for $1.5 \mathrm{~min}$, and final extension for 7 min at $72{ }^{\circ} \mathrm{C}$ (Veriti; ThermoFisher Scientific, Ecublens, Suisse).

To confirm the identification of Burkholderia cepacia complex $(B c c)$-like isolates, a PCR targeting the recA gene with the recA primers (BCR1 and BCR2) specific to $B c c$ which led to the amplification of a $1043 \mathrm{bp}$ fragment was performed 
(Mahenthiralingam et al. 2000). Pseudomonas aeruginosalike isolates were screened by PCR for the presence of the ecf $X$ gene, a $P$. aeruginosa species-specific marker (Lavenir et al. 2007). Those identified as Stenotrophomonas maltophilia were confirmed according to the procedure described by Pinot et al. (2011).

Amplified DNA was resolved by electrophoresis in $0.8 \%$ agarose gels, stained with ethidium bromide, and photographed using a Gel Doc 1000 camera (Bio-Rad). Sequencing was performed on the 16S rRNA gene PCR fragment using primers 16S-906R (Weisburg et al. 1991). Sequencing was performed by Biofidal (Villeurbanne, France). Partial 16S rDNA sequences of about $1000 \mathrm{bp}$ were obtained. Identification at the species level was performed by comparison with the Ribosomal Database Project database (http://rdp.cme.msu.edu/) and by using Blast (http://blast.ncbi.nlm.nih.gov/Blast.cgi).

\section{Antibiotic resistance test}

Susceptibility to antimicrobial agents was determined by the standard Kirby-Bauer disk diffusion method for all bacterial endocytobionts. Twenty-three antibiotics were chosen on the basis of their ability to highlight supplementary antibiotic resistance in comparison to natural resistance of each species. Inocula were prepared by the direct inoculum method from 24-h growth on MuellerHinton agar plates and adjusted to a 0.5 McFarland standard. Mueller-Hinton medium agar (Dutscher, Issy-lesmoulineaux, France) was swabbed with the culture. The disks (Bio-Rad) were placed in upright position on the surface of the test plates [TIC $=$ ticarcillin $75 \mu \mathrm{g}$, TCC $=$ ticarcillin clavunalic-acid 75/10 $\mu \mathrm{g}, \mathrm{PIP}=$ piperacillin $75 \mu \mathrm{g}, \mathrm{PPT}=$ piperacillin-tazobactam 75/10 $\mu \mathrm{g}, \mathrm{CAZ}=$ ceftazidime $30 \mu \mathrm{g}, \mathrm{IPM}=$ imipenem $10 \mu \mathrm{g}, \mathrm{GM}=$ gentamicin $15 \mu \mathrm{g}, \mathrm{TM}=$ tobramycin $10 \mu \mathrm{g}, \mathrm{AKN}=$ amikacin $30 \mu \mathrm{g}, \mathrm{CIP}=$ ciprofloxacin $5 \mu \mathrm{g}, \mathrm{FEP}=$ cefepime $30 \mu \mathrm{g}$, $\mathrm{CPO}=$ cefpirome $30 \mu \mathrm{g}, \mathrm{MEM}=$ meropenem $10 \mu \mathrm{g}$, NET $=$ netilmicin $30 \mu \mathrm{g}, \mathrm{CHL}=$ chloramphenicol $30 \mu \mathrm{g}$, TET $=$ tetracyclin $30 \mu \mathrm{g}, \mathrm{ATM}=$ aztreonam $10 \mu \mathrm{g}, \mathrm{CS}=$ colistin $50 \mu \mathrm{g}$, DORI = doripenem $10 \mu \mathrm{g}, \mathrm{LVX}=$ levofloxacin $5 \mu \mathrm{g}$, OFX = ofloxacin $5 \mu \mathrm{g}$, SXT = trimethoprim/sulfamethoxazole $1.25 / 23.75 \mu \mathrm{g}, \mathrm{PEF}=$ pefloxacin $5 \mu \mathrm{g}]$. After incubation of the plates at $37^{\circ} \mathrm{C}$ for 18-24 h, the plates were scored for growth by measuring the diameter of the inhibition zone with respect to each disc. Interpretations were established following the recommendations of the antibiogram committee of the French Society of Microbiology (EUCAST 2010 and 2017). The quality control strain for antimicrobial susceptibility testing was Pseudomonas aeruginosa ATCC 27853.

\section{Virulence assays}

Virulence of human opportunistic pathogens isolated as bacterial endocytobionts was determined using plate-killing assay with the alternative amoebal model, $D$. discoideum (Cosson et al. 2002; Froquet et al. 2008). From the overnight bacterial culture, the optical density (OD) at $600 \mathrm{~nm}$ was adjusted to 1.5 by dilution in LB. One milliliter of each adjusted bacterial suspension was plated on Sm Agar (Formedium, Hustanton, UK) medium. The plates were allowed to dry for $1 \mathrm{~h}$ to obtain a dry bacterial layer.

Cells of $D$. discoideum AX2 were washed twice in HL5 medium by centrifugation at $1000 \mathrm{~g}$ for $10 \mathrm{~min}$. The amoebal suspension was adjusted to $2 \times 10^{6}$ cells $\mathrm{mL}^{-1}$ and serial dilutions were realized in order to obtain spot of five $\mu \mathrm{L}$ of D. discoideum with 14,000 at 39 cells. Each spot was spotted on the bacterial lawn. The plates were incubated at $22.5^{\circ} \mathrm{C}$ for 5 days and appearance of phagocytic plaques was checked at the end of the incubation time. This assay was performed in triplicate.

Strains of P. aeruginosa PT5 (Favre-Bonte 2003) and K. pneumoniae $\mathrm{KpGe}$ (kindly provided by Pierre Cosson) were used as negative (virulent $P$. aeruginosa PT5 should be non-permissive for $D$. discoideum growth) and positive controls (K. pneumoniae KpGe non-virulent strain should be permissive for $D$. discoideum) respectively, for each assay.

In order to interpret the results, three categories were defined by Adamek et al. (2011): non-virulent (less than 400 amoebae for lysis plaque formation), low-virulent (4002500 amoebae for lysis plaque formation), and virulent (more than 2500 amoebae).

\section{Statistical analyses}

To investigate the relationships between antibiotic resistance and amoebal or soil origin, a principal component analysis was performed using a table containing 50 rows (bacterial isolates) and 23 variables (antibiotics) on the data corresponding to the diameter of the inhibition zone using $\mathrm{R} \circledast$ software, version 3.1.2 (Thioulouse and Dray 2007).

\section{Results}

\section{Abundance and diversity of FLA}

Using the MPN method, we detected 8480, 7186, 8462, and $563 \mathrm{CFU}$ (g drywt soil $)^{-1}$ in soil samples from Burkina Faso, garden soil from Vietnam (V1), mining soil from Vietnam (V2), and agricultural pasture from France, respectively.

We further analyzed 208 SSU-rDNA sequences of amoebae from Burkina Faso, 359 from Vietnam, and 133 in France. Culturable FLA were identified at the genus level and the 
Fig. 1 Diversity of culturable FLA at genus level in Burkina Faso, Vietnam (V1 and V2), and France soils
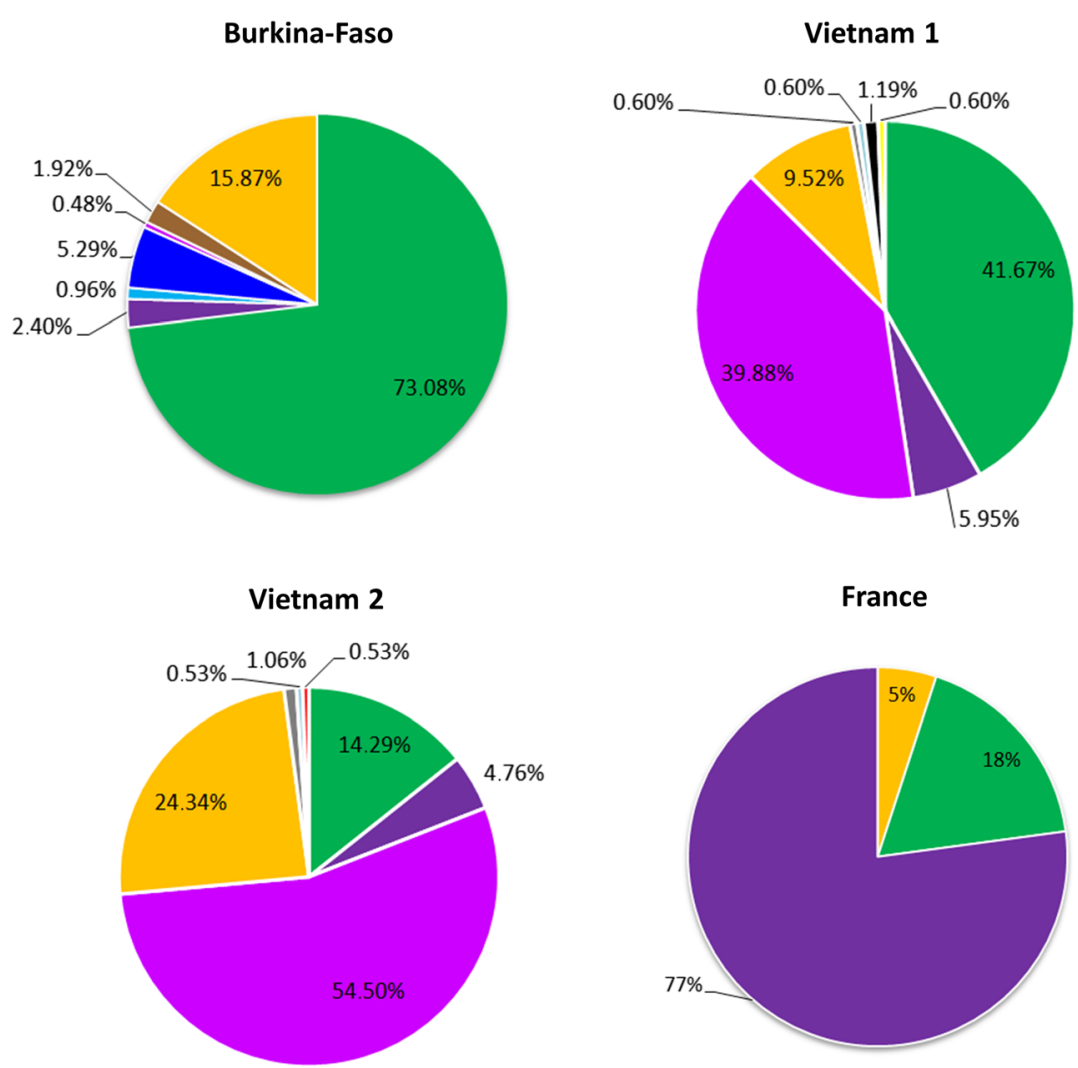

- Tetramitus

- Acanthamoeba = Learamoeba

Micriamoeba

- Vermamoeba $\begin{array}{lll}\text { Willaertia } & \text { Naegleria } & \text { Vannella } \\ \text {-Stachyamoeba } & \text { Mycetozoa } & \text { Unidentified }\end{array}$ diversity per site is shown in Fig. 1. Tetramitus was the most prevalent genus in the Burkina Faso soil (73\%) and garden soil V1 (42\%) while Naegleria and Acanthamoeba were dominant genera in the mining soil V2 (55\%) and French soil (77\%). Few Naegleria were found in Burkina Faso (0.5\%) and none was found in France. A small amount of Acanthamoeba was found in Burkina Faso (2.4\%) as well as in V1 and V2 (5.9 and 4.8\%, respectively). Some genera were present in only one soil. For example, Learamoeba, Willaertia, and Vannella were only detected in Burkina Faso (1, 5, and 2\% respectively), while Stachyamoeba were detected only in V2 and Valhkampfia and Mycetozoa only in V1 (1.2 and $0.6 \%$, respectively). Genera such as Vermamoeba and Micriamoeba were only observed in Vietnam soils.

\section{Isolation and identification of bacterial endocytobionts}

As amoebae were grown on $E$. coli, a high proportion of colonies (i.e., up to $52 \%$ ) were identified as $E$. coli-like based on sequencing of the $16 \mathrm{~S}$ rDNA gene. Our study then focused on 37, 20, and 3 bacterial endocytobionts from soils collected in Burkina Faso, Vietnam, and France, respectively. Bacteria belonging to Firmicutes (50\%), Actinobacteria (12\%), Bacteroidetes (1.6\%), and Proteobacteria (37\%) phyla were isolated (Table 1). Most bacterial endocytobionts belonging to Firmicutes were isolated within amoebae from Burkina Faso and found to be closely related to Bacillus, Paenibacillus, and Lysinibacillus species. These bacteria as well as the Enterococcus faecium-like isolates were recovered from Acanthamoeba, Tetramitus, Willaertia, Micriamoeba, and Mycetozoa from the four studied soils. All bacterial endocytobionts belonging to Actinobacteria and identified as Micrococcus luteus, Kocuria rhizophila, or Brevibacterium iodinum were isolated within amoebal genera, i.e., Naegleria, Acanthamoeba, Mycetozoa, and Tetramitus, from Burkina Faso and Vietnam soils. Regarding Bacteroidetes phylum, Chryseobacterium sp. was the only isolate obtained from Micriamoeba in V2. Finally, most isolates belonging to Proteobacteria were isolated from amoebae in Burkina Faso. Bacteria such as Collimonas fungivorans, Brevundimonas vesicularis, Agrobacterium tumefaciens, and Burkholderia sediminicola were found in several amoebal genera from Burkina Faso and both Vietnam soils. Regarding opportunistic pathogenic species, we isolated two Stenotrophomonas maltophilia from two amoebal genera (Micriamoeba and Tetramitus) from two different soils (Burkina Faso and V2). Eight isolates of Pseudomonas aeruginosa were also found in two amoebal genera (Tetramitus and Willaertia) and only from 
Table 1 Identification of amoebae-associated bacteria according to $16 \mathrm{~S}$ rDNA gene sequencing. The number represents the number of each bacterial isolate. In parenthesis, the percentage represents the percentage of identity

\begin{tabular}{|c|c|c|c|c|c|c|c|c|}
\hline \multirow{2}{*}{$\begin{array}{l}\text { Identification of } \\
\text { bacterial species }\end{array}$} & \multirow{2}{*}{$\begin{array}{l}\text { Number of } \\
\text { isolates }\end{array}$} & \multirow[t]{2}{*}{ Sampling areas } & \multicolumn{6}{|c|}{ Free-living amoebae } \\
\hline & & & Tetramitus & Willaertia & Micriamoeba & Acanthamoeba & Naegleria & Mycetozoa \\
\hline \multicolumn{9}{|l|}{ Actinobacteria } \\
\hline $\begin{array}{l}\text { Brevibacterium iodinum } \\
\text { strain ATCC } 15728 \\
(99 \%)\end{array}$ & 1 & $\mathrm{~V} 2$ & & & & & 1 & \\
\hline $\begin{array}{l}\text { Kocuria rhizophila strain } \\
\text { R-42745 (99\%) }\end{array}$ & 2 & $\mathrm{~V} 1, \mathrm{~V} 2$ & & & & & $2(1)^{*}$ & \\
\hline $\begin{array}{l}\text { Micrococcus luteus strain } \\
\text { VTM4R57 (99\%) }\end{array}$ & 4 & Burkina Faso, V1 (3) & 1 & & & 2 & & 1 \\
\hline \multicolumn{9}{|l|}{ Bacteroidetes } \\
\hline $\begin{array}{l}\text { Chryseobacterium sp. C16 } \\
(99 \%)\end{array}$ & 1 & $\mathrm{~V} 2$ & & & 1 & & & \\
\hline \multicolumn{9}{|l|}{ Firmicutes } \\
\hline $\begin{array}{l}\text { Bacillus sp. } 1 \text { RIFA } 306 \\
(99 \%)\end{array}$ & 15 & $\begin{array}{l}\text { Burkina Faso (7), V1 (4), } \\
\text { V2 (1), France (3) }\end{array}$ & 1 & 1 & 2 & 10 & & 1 \\
\hline $\begin{array}{l}\text { Brevibacillus fluminis } \\
\text { strain CJ71 (97\%) }\end{array}$ & 1 & Burkina Faso & & $1 *$ & & & & \\
\hline $\begin{array}{l}\text { Enterococcus faecium } \\
\text { strain E39 }(98 \%)\end{array}$ & 2 & Burkina Faso & $2 *$ & & & & & \\
\hline $\begin{array}{l}\text { Lysinibacillus sp. } \\
\text { 6BK6Y10 (97\%) }\end{array}$ & 3 & Burkina Faso (2), V1 (1) & & 2 & & 1 & & \\
\hline $\begin{array}{l}\text { Paenibacillus sp. TA_ } \\
\text { AM1 } \\
\text { strain TA_AM1 (99\%) }\end{array}$ & 9 & $\begin{array}{l}\text { Burkina Faso (7), V1, } \\
\quad \text { V2 (2) }\end{array}$ & 2 & 1 & $1^{*}$ & 5 & & \\
\hline \multicolumn{9}{|l|}{ Proteobacteria } \\
\hline $\begin{array}{l}\text { Agrobacterium } \\
\text { tumefaciens } \\
(99 \%)\end{array}$ & 1 & Burkina Faso & & 1 & & & & \\
\hline $\begin{array}{l}\text { Brevundimonas vesicularis } \\
\text { strain KK6 }(98 \%)\end{array}$ & 1 & $\mathrm{~V} 2$ & & & & & 1 & \\
\hline $\begin{array}{l}\text { Burkholderia cepacia } \\
\text { strain H-2 (99\%) }\end{array}$ & 1 & $\mathrm{~V} 2$ & & & & 1 & & \\
\hline $\begin{array}{l}\text { Burkholderia sediminicola } \\
\text { strain GM297 (91\%) }\end{array}$ & 5 & Burkina Faso & & & $4^{*}$ & $1 *$ & & \\
\hline $\begin{array}{l}\text { Collimonas fungivorans } \\
\text { strain GM303 (99\%) }\end{array}$ & 1 & Burkina Faso & & & & 1 & & \\
\hline $\begin{array}{l}\text { Enhydrobacter sp. ITCr12 } \\
\quad(99 \%)\end{array}$ & 1 & V1 & & & 1 & & & \\
\hline $\begin{array}{l}\text { Haematobacter } \\
\text { massiliensis strain } \\
\text { KC2145 }(99 \%)\end{array}$ & 1 & $\mathrm{~V} 2$ & & & 1 & & & \\
\hline $\begin{array}{l}\text { Pseudomonas aeruginosa } \\
\text { strain mmp1 (99\%) }\end{array}$ & 8 & Burkina Faso & 6 & 2 & & & & \\
\hline $\begin{array}{l}\text { Pseudomonas sp. CB1 } \\
\quad(98 \%)\end{array}$ & 1 & Burkina Faso & & & & 1 & & \\
\hline $\begin{array}{l}\text { Stenotrophomonas } \\
\text { maltophilia isolate } 177 \\
(99 \%)\end{array}$ & 2 & Burkina Faso, V2 & 1 & & 1 & & & \\
\hline
\end{tabular}

*Representative isolates that were not characterized for antibiotic resistance properties

Burkina Faso soil. Finally, a Burkholderia cepacia-like isolate and a Haematobacter massiliensis-like isolate were recovered from Acanthamoeba and Micriamoeba, respectively, from the V2 soil. Identification of $P$. aeruginosa, S. maltophilia, and $B$. cepacia isolates was confirmed by a positive PCR amplification with specific gene markers.

\section{Antibiotic resistance profile of bacterial endocytobionts}

Sixty strains were tested to determine the antibiotic phenotype. Ten of them did not grow homogeneously on the agar medium and their antibiotic profiles were not determined. 
Fig. 2 Principal component plot $(\mathrm{PC} 1 \times \mathrm{PC} 2)$ generated from the antibiotic resistance properties of bacterial isolates from free-living amoebae. The data table indicates the diameter of the inhibition zone. The groups of isolates are drawn based on amoebal (a) or soil (b) origin. Plot (c) indicates the role of the various antibiotics on the ordination. $\mathrm{R}$ and $\mathrm{S}$ indicate resistant versus susceptible phenotypes
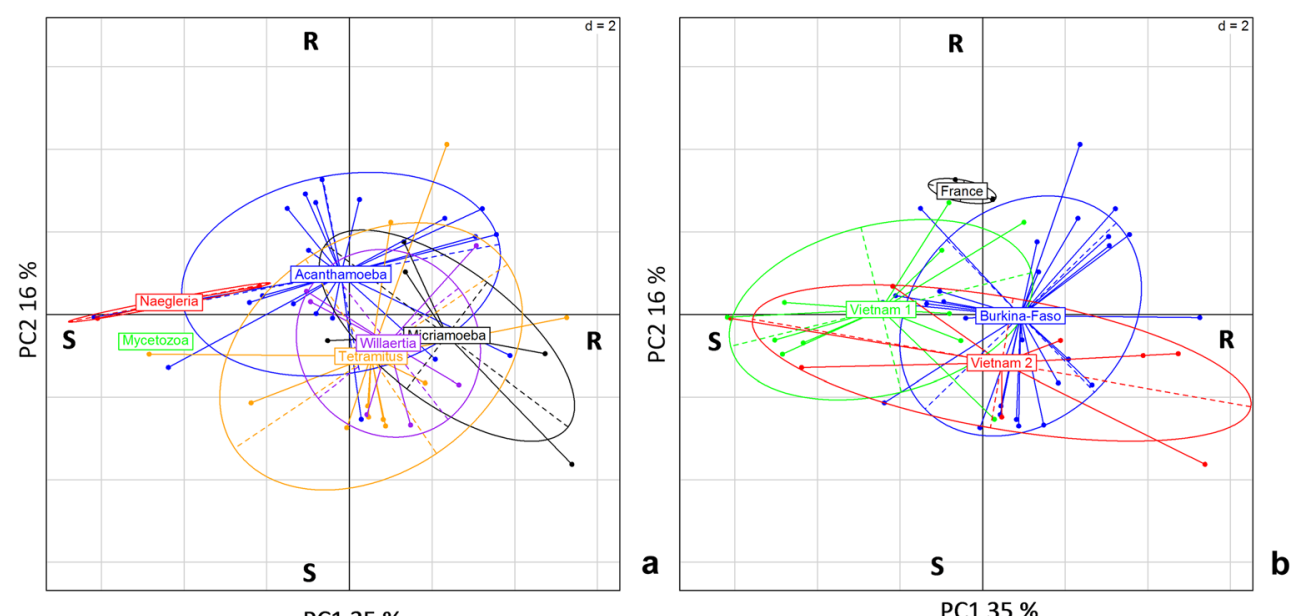

PC1 $35 \%$

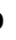

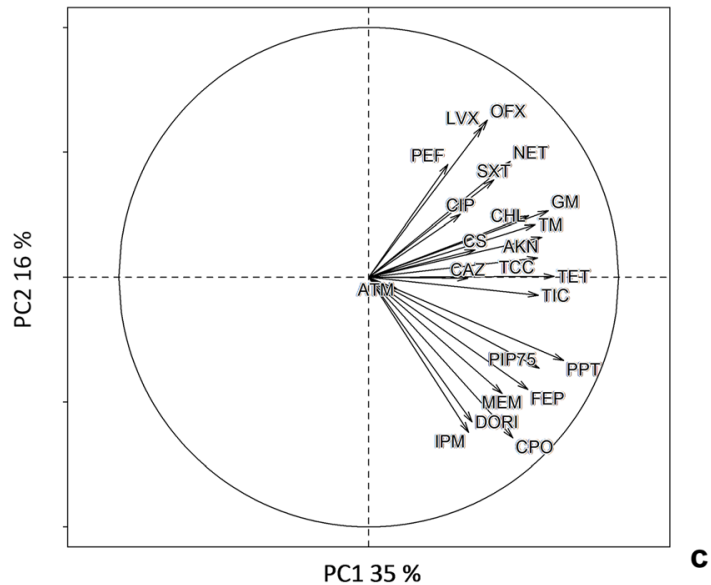

A number of antimicrobial agents appear to be active against $H$. massiliensis. Currently, there are no interpretive minimum inhibitory concentration (MIC) breakpoints for isolates of this species. Nevertheless, carbapenems, aztreonam, ticarcillin, and ticarcillin-clavulanic acid appeared to have good activity against this isolate. In contrast, MICs to aminoglycosides, fluoroquinolones, tetracycline, chloramphenicol, and piperacillin were higher (data not shown).

Antibiotic resistance phenotypes of opportunistic pathogens including P. aeruginosa, S. maltophilia, and B. cepacia were interpreted according to EUCAST recommendations. Besides natural resistances, all of the eight strains of $P$. aeruginosa isolated from Tetramitus or Willaertia were resistant to trimetho$\mathrm{prim} / \mathrm{sulfamethoxazole}$. Five strains were classified intermediate towards aztreonam. On the opposite, the two strains of S. maltophilia isolated from Micriamoeba in V2 soil and from Tetramitus in Burkina Faso soil showed sensitive phenotypes against trimethoprim/sulfamethoxazole. In addition to natural resistances, B. cepacia, isolated from Acanthamoeba from V2 soil, was resistant to tetracyclin.

A principal component analysis was performed in order to evaluate whether relationships might exist between the antibiotic resistance profile of isolates and their associated amoebae and/or soil origin (Fig. 2a, b, c). The factorial map showed a resistance gradient along PC1 with strains isolated from Naegleria and Mycetozoa being the most susceptible towards antibiotics except quinolones. These strains were closely related to Brevundimonas vesicularis, Brevibacterium iodinum, and Kocuria rhizophilia for Naegleria isolates and to Micrococcus luteus and Bacillus sp. for Mycetozoa. However, in these two genera (Mycetozoa and Naegleria), the number of isolates tested was low (two and three, respectively) and this observation might explain the differences. Furthermore, one can observe an important overlap of the isolates from the other amoebal genera. All these data then suggest that no link exists between amoebal genera and the antibiotic resistance of bacterial endocytobionts (Fig. 2a, c). Similarly, no link was seen between the geographical origin of soil and their characteristics and the antibiotic resistance of bacterial endocytobionts (Fig. $2 b, c)$. Furthermore, in these soils, we found bacterial endocytobionts equally characterized with low or high MIC.

\section{Virulence of opportunistic bacterial endocytobionts}

The eight isolates of $P$. aeruginosa (MEEB-Am5.1 to 5.8) were determined to be virulent strains because more than 


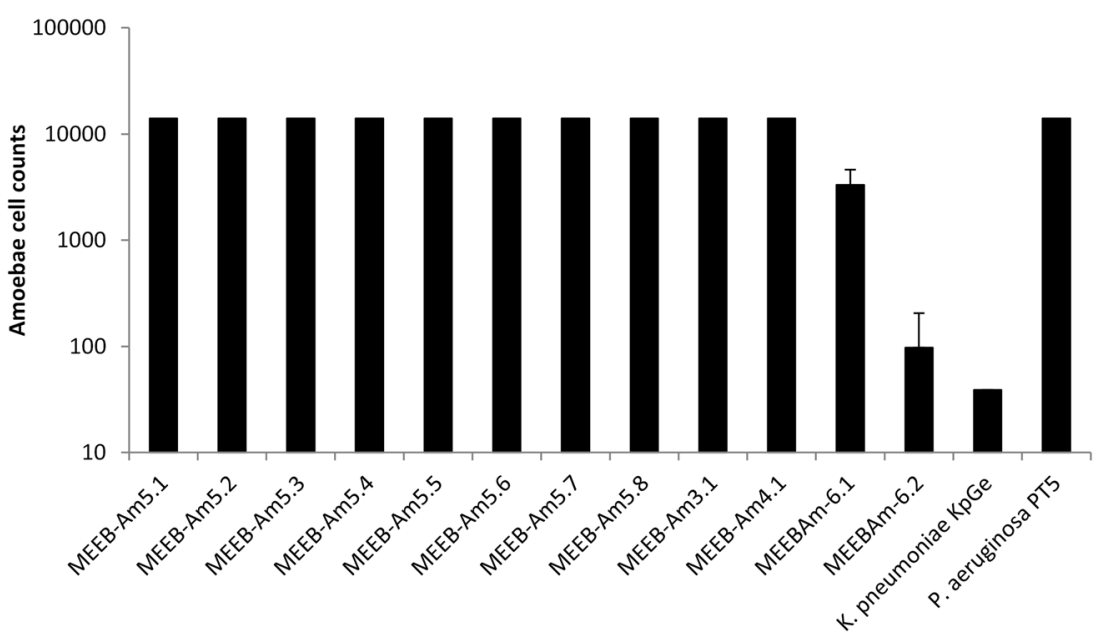

Fig. 3 D. discoideum plate-killing assay with different human opportunistic bacterial endocytobionts: P. aeruginosa isolates (MEEB-Am5.1 to 5.8), B. cepacia (MEEB-Am3.1), H. massiliensis (MEEB-Am4.1), and S. maltophilia (MEEB-Am6.1 and 6.2). Bars representing the number of

2500 cells of amoebae were needed to form lysis plaques similar to the $P$. aeruginosa PT5 control strain (Fig. 3). Isolates of $B$. cepacia MEEB-Am3.1, H. massiliensis MEEB-Am4.1, and S. maltophilia MEEB-Am6.1 were also virulent strains since more than 2500 cells of amoebae were needed to form lysis plaque. However, the other isolate of S. maltophilia MEEB-Am6.2 was determined to be a nonvirulent strain as fewer than 400 amoebae were needed to form lysis plaques similar to the control strain K. pneumoniae KpGe.

\section{Discussion}

In the environment, the study of amoebal diversity in soils without a priori has been poorly explored. To our knowledge, this is the first study on culturable FLA diversity in various contrasting soils as most studies have focused on amoebal diversity in waters (Thomas et al. 2006; Delafont et al. 2013) or on the environmental prevalence of only one amoebal genus (Geisen et al. 2014; Reyes-Batlle et al. 2016). This study focuses on the diversity of culturable amoebae and their bacterial endocytobionts in soil samples collected from different geographical areas (Burkina Faso, Vietnam, and France). It showed that soils host diverse culturable FLA which also hold a high diversity of culturable bacterial species. Indeed, FLA diversity is different according to the origin of the soil. These differences could be due to soils characteristics (such as $\mathrm{pH}$ which is lower in France and in V2 soils), to moisture linked to the climate, and soil temperature during sampling. These physical parameters have been described to affect the ecology of FLA (Rodríguez-Zaragoza 1994). However, in our study, no robust correlation can be performed between soil characteristics and amoebal diversity due to the amoebae necessary to form a lysis plaque on the bacterial lawn. $P$. aeruginosa PT5 and $K$. pneumoniae $\mathrm{KpGe}$ were used as negative and positive controls, respectively. Data represent means \pm standard deviation from two independent experiments in triplicate

low number of soil samples tested. In each soil, a predominant genus was identified: Tetramitus in Burkina Faso and V1, Naegleria in V2, and Acanthamoeba in France. Previous studies showed that Acanthamoeba and Vermamoeba are the most represented genus of FLA in the environment and more particularly in industrial waters (Scheikl et al. 2014), hospital water networks (Thomas et al. 2006; Muchesa et al. 2017), drinking water (Delafont et al. 2013), cooling towers (Atlan et al. 2012; Scheikl et al. 2016), and soils from the Negev Desert (Rodriguez Zaragoza et al. 2005). Our results on the French soil are in accordance to these previous studies. However, our results are original for the three other soils. To our knowledge, Tetramitus is poorly studied in the literature and only one study showed that the predominant amoebal genus in the environment is Tetramitus (Farra et al. 2017). Recently, a study on treated and untreated water samples showed that Naegleria was the major genus found in water samples (Majid et al. 2017). Tetramitus and Naegleria are frequently found in the environment but often in a minor proportions (Delafont et al. 2013; Ramirez et al. 2014; Mulec et al. 2016; Delafont et al. 2016; Muchesa et al. 2017). In our soils, minor amoebal genera such as Willaertia, Vannella, or Learamoeba were only detected in one out of the four soils, which suggests that each genus could be used as an indicator of soil type and/or geographical area. However, this result must be taken with caution due to the low number of soil samples tested and the limited number of FLA isolated. Also, it is important to emphasize that the use of NNA-E. coli plates to recover FLA is a limit of the method. Indeed, only FLA that are able to grow on this type of media (with E. coli as food) could be identified and it is possible that some genera may have been missed.

Regarding bacterial endocytobionts, this work shows several culturable bacterial species associated with FLA in soils. 
Firmicutes isolates such as Paenibacillus sp., Lysinibacillus sp., Bacillus sp., and B. fluminis were associated to different FLA genera and mostly from Acanthamoeba. These bacteria were previously found in association with FLA in drinking water (Delafont et al. 2013, 2016). Furthermore, Paenibacillus sp. was even characterized as a symbiont in Acanthamoeba (Maschio et al. 2015). While these bacteria are environmental genera (Guo et al. 2015; Gomes Cavados et al. 2017), some strains belonging to Paenibacillus or Bacillus such as Bacillus cereus and Paenibacillus thiaminolyticus sometimes cause human infections (Ouyang et al. 2008; Ikeda et al. 2015). Even if none of these pathogens were isolated, some isolates were found to be closely related to other human opportunistic pathogens, i.e., S. maltophilia, $P$. aeruginosa, and B. cepacia. These results are in accordance with other studies characterizing the diversity of intraamoebal bacteria in drinking water networks (Delafont et al. 2013, 2016). Indeed, Stenotrophomonas and Pseudomonas are often the major genus isolated in amoebal microbiome (Delafont et al. 2016). However, these studies did not identify these intra-amoebal bacteria at the species level. Co-culture studies with Acanthamoeba or Vermamoeba showed the ability of S. maltophilia and P. aeruginosa to resist amoebal digestion and multiply inside (Marolda et al. 1999; Cateau et al. 2014; José Maschio et al. 2015). Our data then clearly confirmed the potential presence of these pathogens associated with FLA. Those reports are of public health concern as both species can be responsible of both nosocomial and community-acquired infections (Looney et al. 2009; Mariappan et al. 2013; Winstanley et al. 2015). Another species belonging to Proteobacteria was isolated from Micriamoeba: Haematobacter massiliensis. As far as we know, this species has never been isolated in amoebal microbiome. This report is interesting as $H$. massiliensis has been isolated from blood samples from patients with septicaemia (Buscher et al. 2010). The advantage of using culturable approach is that it allows characterizing both genetically and phenotypically the bacterial species isolated from the amoeba. For example, S. maltophilia was described in Tetramitus but also in Micriamoeba. However, this association could not be extrapolated to any environmental sampling.

Intra-amoebal bacteria such as Mycobacteria-like bacteria were not found within FLA in this study. This could be related to the use of TSA $1 / 10$ and Drigalski media which may not be appropriate for the isolation of these particular species and may give a non-exhaustive overview of the diversity of bacterial endocytobiont. Furthermore, these media may not be adapted for the growth of demanding bacteria. Also, the use of $E$. coli as a food to isolate FLA might hamper the growth of minor intra-amoebal bacteria and/or those with a low growth rate. It would then be interesting to use various culture media and various feeding microorganisms, i.e.,
Saccharomyces cerevisiae, in order to get a more exhaustive picture of the diversity of bacterial endocytobionts.

One advantage of using a culture-based approach is the possibility to characterize the phenotype of bacterial isolates in terms of antimicrobial resistance and virulence properties. Among bacterial endocytobionts, antibiotic resistance phenotypes were diverse according to the own natural resistance of each species. The variability in antibiotic resistance profiles looked to be more related to bacterial genera rather than amoebal host. Furthermore, the PCA analyses showed there was no link between antibiotic resistance of bacterial endocytobionts and their amoebal host.

Concerning opportunistic pathogens, antibiotic resistance phenotypes also varied widely. The eight isolates of $P$. aeruginosa displayed one more resistance than natural resistances known to be due to the presence of the various efflux pumps (Hancock 1998). Similarly, B. cepacia was resistant to 11 different antibiotics with five resistances towards betalactams. As B. cepacia is considered as naturally resistant to beta-lactams, aminoside, and colistin (Hancock 1998), this B. cepacia-like isolate did not showed additional resistances. Regarding S. maltophilia, no supplementary antibiotic resistance was detected compared to natural resistance. These strains displayed an antibiotic resistance phenotype close to S. maltophilia strains isolated from French soils and different to MDR S. maltophilia strains isolated from Tunisia and Burkina Faso soils (Deredjian et al. 2016).

The isolate identified as H. massiliensis showed high MICs towards different classes of antibiotics including aminoglycosides, fluoroquinolones, tetracycline, chloramphenicol, and piperacillin. Tetracycline and chloramphenicol are usually effective against this species isolated from clinical specimens (Helsel et al. 2007). In our study, these molecules displayed a poor activity against the strain isolated in Micriamoeba. This isolate was also found to be virulent. It has to be noted that the antibiotic resistance properties of this species as well as its virulence are still poorly documented.

In our study, all $P$. aeruginosa isolates and B. cepacia strains were found to be virulent strains. These observations are original, because in previous reports, most virulent species of $P$. aeruginosa or B. cepacia were isolated from clinical environments (Leitao et al. 2010; Streeter et al. 2016) and few data are available concerning the virulence properties of soil isolates belonging to these species. Furthermore, P. aeruginosa bacteria are rarely isolated from soil due to its low occurrence in this environment (Selezska et al. 2012; Deredjian et al. 2014). Also, both virulent and non-virulent phenotypes were observed for the two isolates of $S$. maltophilia. It is quite surprising to find virulent $S$. maltophilia isolate in soil amoebae whereas most clinical or environmental isolates of S. maltophilia are considered as non-virulent (Adamek et al. 2011). 


\section{Conclusion}

Our study confirmed the worldwide diversity of culturable FLA in soils whatever their characteristics ( $\mathrm{pH}$, climate, season, ...) are. Our results highlighted dominant genera as Tetramitus in Burkina Faso and V1, Naegleria in V2, and Acanthamoeba in France. The potential of these FLA to host various bacterial species including opportunistic pathogens such as $P$. aeruginosa, $S$. maltophilia, B. cepacia, and H. massiliensis was also shown. Thanks to the culturable approach, this work allowed (i) to associate a bacterial species to an amoebal genus, which is not the case using metagenomic studies, and (ii) to characterize the antibiotic resistance profile and the virulence properties of each opportunistic bacterial endocytobiont. These endocytobionts displayed natural antibiotic resistance profiles and variable virulence properties. Among them, some isolates were highly virulent as described for clinical strains. As literature reported that virulence and antibiotic resistance of intra-amoebal bacteria could be intensified (Loret and Greub 2010) after passing through the amoeba, further work will be performed to evaluate these properties among the various bacterial endocytobionts isolated in this study. Co-culture experiments could be performed to assess the ability of bacterial endocytobionts to multiply within amoebae and then evaluate whether their release in large number in the environment would be at risk for human health.

Acknowledgements We wish to thank Nicole Lloyd, a native English speaker, for reviewing this article prior to publication.

Funding information This work was supported by the CNRS (Centre National de la Recherche Scientifique). Elodie Denet was funded by a grant from the Ministère de l'Education Nationale, de l'Enseignement Supérieur et de la Recherche.

\section{References}

Adamek M, Overhage J, Bathe S et al (2011) Genotyping of environmental and clinical Stenotrophomonas maltophilia isolates and their pathogenic potential. PLoS One 6:e27615. https://doi.org/10.1371/ journal.pone. 0027615

Amissah NA, Gryseels S, Tobias NJ et al (2014) Investigating the role of free-living amoebae as a reservoir for Mycobacterium ulcerans. PLoS Negl Trop Dis 8:e3148. https://doi.org/10.1371/journal.pntd. 0003148

Atlan D, Coupat-Goutaland B, Risler A et al (2012) Micriamoeba tesseris nov. gen. nov. sp.: a new taxon of free-living small-sized amoebae non-permissive to virulent Legionellae. Protist 163:888-902. https://doi.org/10.1016/j.protis.2012.04.006

Balczun C, Scheid P (2017) Free-Living amoebae as hosts for and vectors of intracellular microorganisms with public health significance. Viruses 9:65. https://doi.org/10.3390/v9040065

Buscher A, Li L, Han XY, Trautner BW (2010) Aortic valve endocarditis possibly caused by a Haematobacter-like species. J Clin Microbiol 48:3791-3793. https://doi.org/10.1128/JCM.00238-10
Canteón R (2009) Antibiotic resistance genes from the environment: a perspective through newly identified antibiotic resistance mechanisms in the clinical setting. Clin Microbiol Infect 15:20-25. https://doi.org/10.1111/j.1469-0691.2008.02679.x

Cateau E, Maisonneuve E, Peguilhan S et al (2014) Stenotrophomonas maltophilia and Vermamoeba vermiformis relationships: bacterial multiplication and protection in amoebal-derived structures. Res Microbiol 165:847-851. https://doi.org/10.1016/j.resmic.2014.10. 004

Cirillo JD, Falkow S, Tompkins LS, Bermudez LE (1997) Interaction of Mycobacterium avium with environmental amoebae enhances virulence. Infect Immun 65:3759-3767

Cosson P, Zulianello L, Join-Lambert O et al (2002) Pseudomonas aeruginosa virulence analyzed in a Dictyostelium discoideum host system. J Bacteriol 184:3027-3033. https://doi.org/10.1128/JB.184. 11.3027-3033.2002

De Man JC (1975) The probability of most probable numbers. Appl Microbiol Biotechnol 1:67-78

Delafont V, Bouchon D, Héchard Y, Moulin L (2016) Environmental factors shaping cultured free-living amoebae and their associated bacterial community within drinking water network. Water Res 100:382-392. https://doi.org/10.1016/j.watres.2016.05.044

Delafont V, Brouke A, Bouchon D et al (2013) Microbiome of free-living amoebae isolated from drinking water. Water Res 47:6958-6965. https://doi.org/10.1016/j.watres.2013.07.047

Deredjian A, Alliot N, Blanchard L et al (2016) Occurrence of Stenotrophomonas maltophilia in agricultural soils and antibiotic resistance properties. Res Microbiol 167:313-324. https://doi.org/ 10.1016/j.resmic.2016.01.001

Deredjian A, Colinon C, Hien E et al (2014) Low occurrence of Pseudomonas aeruginosa in agricultural soils with and without organic amendment. Front Cell Infect Microbiol. https://doi.org/10. 3389/fcimb.2014.00053

Evstigneeva A, Raoult D, Karpachevskiy L, La Scola B (2009) Amoeba co-culture of soil specimens recovered 33 different bacteria, including four new species and Streptococcus pneumoniae. Microbiology 155:657-664. https://doi.org/10.1099/mic.0.022970-0

Farra A, Bekondi C, Tricou Vet al (2017) Free-living amoebae isolated in the Central African Republic: epidemiological and molecular aspects. Pan Afr Med J. 10.11604/pamj.2017.26.57.9021

Favre-Bonte S (2003) Biofilm formation by Pseudomonas aeruginosa: role of the C4-HSL cell-to-cell signal and inhibition by azithromycin. J Antimicrob Chemother 52:598-604. https://doi. org/10.1093/jac/dkg397

Froquet R, Lelong E, Marchetti A, Cosson P (2008) Dictyostelium discoideum: a model host to measure bacterial virulence. Nat Protoc 4:25-30. https://doi.org/10.1038/nprot.2008.212

Garcia-Sanchez A, Ariza C, Ubeda J et al (2013) Free-living amoebae in sediments from the Lascaux Cave in France. Int J Speleol 42:9-13. https://doi.org/10.5038/1827-806X.42.1.2

Geisen S, Fiore-Donno AM, Walochnik J, Bonkowski M (2014) Acanthamoeba everywhere: high diversity of Acanthamoeba in soils. Parasitol Res 113:3151-3158. https://doi.org/10.1007/ s00436-014-3976-8

Cavados CFG, Pires ES, Chaves JQ et al (2017) Isolation and genetic characterization of Lysinibacillus sphaericus strains found in mosquito larvae (Diptera: Culicidae). Res Rep Trop Med Volume 8:1720. https://doi.org/10.2147/RRTM.S124066

Greub G, Raoult D (2004) Microorganisms resistant to free-living amoebae. Clin Microbiol Rev 17:413-433. https://doi.org/10.1128/CMR. 17.2.413-433.2004

Guo GN, Zhou X, Zhao R et al (2015) Paenibacillus herberti sp. nov., an endophyte isolated from Herbertus sendtneri. Antonie Van Leeuwenhoek 108:587-596. https://doi.org/10.1007/s10482-0150514-3 
Hancock RE (1998) Resistance mechanisms in Pseudomonas aeruginosa and other non-fermentative gram-negative bacteria. Clin Infect Dis 27:S93-S99

Helsel LO, Hollis D, Steigerwalt AG, et al (2007) Identification of "Haematobacter," a new genus of aerobic gram-negative rods isolated from clinical specimens, and reclassification of Rhodobacter massiliensis as "Haematobacter massiliensis comb. nov." J Clin Microbiol 45:1238-1243. doi: https://doi.org/10.1128/JCM.0118806

Hoffmann R, Michel R (2001) Distribution of free-living amoebae (FLA) during preparation and supply of drinking water. Int J Hyg Environ Health 203:215-219. https://doi.org/10.1078/S1438-4639(04) 70031-0

Huws SA, Morley RJ, Jones MV et al (2008) Interactions of some common pathogenic bacteria with Acanthamoeba polyphaga: interactions of bacteria with amoebae. FEMS Microbiol Lett 282:258265. https://doi.org/10.1111/j.1574-6968.2008.01123.x

Ikeda M, Yagihara Y, Tatsuno K et al (2015) Clinical characteristics and antimicrobial susceptibility of Bacillus cereus blood stream infections. Ann Clin Microbiol Antimicrob. https://doi.org/10.1186/ s12941-015-0104-2

Jacquier N, Aeby S, Lienard J, Greub G (2013) Discovery of new intracellular pathogens by amoebal coculture and amoebal enrichment approaches. J Vis Exp. https://doi.org/10.3791/51055

José Maschio V, Corção G, Rott MB (2015) Identification of Pseudomonas spp. as amoeba-resistant microorganisms in isolates of Acanthamoeba. Rev Inst Med Trop São Paulo 57:81-83. https:// doi.org/10.1590/S0036-46652015000100012

Lavenir R, Jocktane D, Laurent F et al (2007) Improved reliability of Pseudomonas aeruginosa PCR detection by the use of the speciesspecific ecfX gene target. J Microbiol Methods 70:20-29. https:// doi.org/10.1016/j.mimet.2007.03.008

Leitao JH, Sousa SA, Ferreira AS et al (2010) Pathogenicity, virulence factors, and strategies to fight against Burkholderia cepacia complex pathogens and related species. Appl Microbiol Biotechnol 87: 31-40. https://doi.org/10.1007/s00253-010-2528-0

Looney WJ, Narita M, Mühlemann K (2009) Stenotrophomonas maltophilia: an emerging opportunist human pathogen. Lancet Infect Dis 9:312-323

Loret J-F, Greub G (2010) Free-living amoebae: biological by-passes in water treatment. Int J Hyg Environ Health 213:167-175. https://doi. org/10.1016/j.ijheh.2010.03.004

Lu J, Struewing I, Vereen E et al (2016) Molecular detection of Legionella spp. and their associations with Mycobacterium spp., Pseudomonas aeruginosa and amoeba hosts in a drinking water distribution system. J Appl Microbiol 120:509-521. https://doi. org/10.1111/jam. 12996

Mahenthiralingam E, Bischof J, Byrne SK et al (2000) DNA-based diagnostic approaches for identification of Burkholderia cepacia complex, Burkholderia vietnamiensis, Burkholderia multivorans, Burkholderia stabilis, and Burkholderia cepacia genomovars I and III. J Clin Microbiol 38:3165-3173

Majid MAA, Mahboob T, Mong BG et al (2017) Pathogenic waterborne free-living amoebae: an update from selected Southeast Asian countries. PLoS One 12:e0169448

Mariappan V, Vellasamy KM, Thimma J et al (2013) Infection of Burkholderia cepacia induces homeostatic responses in the host for their prolonged survival: the microarray perspective. PLoS One 8:e77418. https://doi.org/10.1371/journal.pone.0077418

Marolda CL, Hauröder B, John MA et al (1999) Intracellular survival and saprophytic growth of isolates from the Burkholderia cepacia complex in free-living amoebae. Microbiology 145:1509-1517

Maschio VJ, Corção G, Bücker F et al (2015) Identification of Paenibacillus as a symbiont in Acanthamoeba. Curr Microbiol 71: 415-420. https://doi.org/10.1007/s00284-015-0869-8
Mohaghegh MA, Azimi Resketi M, Mohammadimanesh R et al (2016) Soil contamination with free-living amoeba in north of Iran. Int J Infect. 10.17795/iji-37923

Muchesa P, Leifels M, Jurzik L et al (2017) Coexistence of free-living amoebae and bacteria in selected South African hospital water distribution systems. Parasitol Res 116:155-165. https://doi.org/10. 1007/s00436-016-5271-3

Mulec J, Dietersdorfer E, Üstüntürk-Onan M, Walochnik J (2016) Acanthamoeba and other free-living amoebae in bat guano, an extreme habitat. Parasitol Res 115:1375-1383. https://doi.org/10. 1007/s00436-015-4871-7

Ouyang J, Pei Z, Lutwick L et al (2008) Paenibacillus thiaminolyticus: a new cause of human infection, inducing bacteremia in a patient on hemodialysis. Ann Clin Lab Sci 38:393-400

Pagnier I, Valles C, Raoult D, La Scola B (2015) Isolation of Vermamoeba vermiformis and associated bacteria in hospital water. Microb Pathog 80:14-20. https://doi.org/10.1016/j.micpath.2015. 02.006

Pelandakis M, Pernin P (2002) Use of multiplex PCR and PCR restriction enzyme analysis for detection and exploration of the variability in the free-living amoeba Naegleria in the environment. Appl Environ Microbiol 68:2061-2065. https://doi.org/10.1128/AEM.68.4.20612065.2002

Pinot C, Deredjian A, Nazaret S et al (2011) Identification of Stenotrophomonas maltophilia strains isolated from environmental and clinical samples: a rapid and efficient procedure: Sten. maltophilia identification. J Appl Microbiol 111:1185-1193. https://doi.org/10.1111/j.1365-2672.2011.05120.x

Ramirez E, Robles E, Bonilla P et al (2005) Occurrence of pathogenic free-living amoebae and bacterial indicators in a constructed wetland treating domestic wastewater from a single household. Eng Life Sci 5:253-258. https://doi.org/10.1002/elsc.200420071

Ramirez E, Robles E, Martinez B et al (2014) Distribution of free-living amoebae in a treatment system of textile industrial wastewater. Exp Parasitol 145:S34-S38. https://doi.org/10.1016/j.exppara.2014.07. 006

Reyes-Batlle M, Wagner C, Zamora-Herrera J et al (2016) Isolation and molecular identification of Vermamoeba vermiformis strains from soil sources in El Hierro Island, Canary Islands, Spain. Curr Microbiol 73:104-107. https://doi.org/10.1007/s00284-016-1035-7

Rodriguez Zaragoza S, Mayzlish E, Steinberger Y (2005) Seasonal changes in free-living amoeba species in the root canopy of Zygophyllum dumosum in the Negev Desert, Israel. Microb Ecol 49:134-141. https://doi.org/10.1007/s00248-003-1056-1

Rodríguez-Zaragoza S (1994) Ecology of free-living amoebae. Crit Rev Microbiol 20:225-241

Rodríguez-Zaragoza S, Garcia S (1997) Species richness and abundance of naked amebae in the rhizoplane of the desert plant Escontria chiotilla (cactaceae). J Eukaryot Microbiol 44:122-126

Scheid P (2014) Relevance of free-living amoebae as hosts for phylogenetically diverse microorganisms. Parasitol Res 113:2407-2414. https://doi.org/10.1007/s00436-014-3932-7

Scheikl U, Sommer R, Kirschner A et al (2014) Free-living amoebae (FLA) co-occurring with legionellae in industrial waters. Eur J Protistol 50:422-429. https://doi.org/10.1016/j.ejop.2014.04.002

Scheikl U, Tsao H-F, Horn M et al (2016) Free-living amoebae and their associated bacteria in Austrian cooling towers: a 1-year routine screening. Parasitol Res 115:3365-3374. https://doi.org/10.1007/ s00436-016-5097-z

Schmitz-Esser S, Toenshoff ER, Haider S et al (2008) Diversity of bacterial endosymbionts of environmental Acanthamoeba isolates. Appl Environ Microbiol 74:5822-5831. https://doi.org/10.1128/ AEM.01093-08

Schroeder JM, Booton GC, Hay J et al (2001) Use of subgenic 18S ribosomal DNA PCR and sequencing for genus and genotype identification of Acanthamoebae from humans with keratitis and from 
sewage sludge. J Clin Microbiol 39:1903-1911. https://oi.org/10. 1128/JCM.39.5.1903-1911.2001

Schulz F, Tyml T, Pizzetti I et al (2015) Marine amoebae with cytoplasmic and perinuclear symbionts deeply branching in the Gammaproteobacteria. Sci Rep. https://doi.org/10.1038/srep13381

Selezska K, Kazmierczak M, Müsken M et al (2012) Pseudomonas aeruginosa population structure revisited under environmental focus: impact of water quality and phage pressure: environmental P. aeruginosa population structure. Environ Microbiol 14:1952-1967. https://doi.org/10.1111/j.1462-2920.2012. 02719. $\mathrm{x}$

Streeter K, Neuman C, Thompson J et al (2016) The characteristics of genetically related Pseudomonas aeruginosa from diverse sources and their interaction with human cell lines. Can J Microbiol 62:233240. https://doi.org/10.1139/cjm-2015-0536

Thioulouse J, Dray S (2007) Interactive multivariate data analysis in R with the ade4 and ade4TkGUI packages. J Stat Softw 22(5). https:// doi.org/10.18637/jss.v022.i05
Thomas V, Herrera-Rimann K, Blanc DS, Greub G (2006) Biodiversity of amoebae and amoeba-resisting bacteria in a hospital water network. Appl Environ Microbiol 72:2428-2438. https://doi.org/10.1128/ AEM.72.4.2428-2438.2006

Tyml T, Skulinová K, Kavan J et al (2016) Heterolobosean amoebae from Arctic and Antarctic extremes: 18 novel strains of Allovahlkampfia, Vahlkampfia and Naegleria. Eur J Protistol 56:119-133. https://doi. org/10.1016/j.ejop.2016.08.003

Weisburg WG, Barns SM, Pelletier DA, Lane DJ (1991) 16S ribosomal DNA amplification for phylogenetic study. J Bacteriol 173:697-703

Winstanley C, McClean S, Drevinek P et al (2015) Phenotypic characterization of an international Pseudomonas aeruginosa reference panel: strains of cystic fibrosis (CF) origin show less in vivo virulence than non-CF strains. Microbiology 161:1961-1977. https:// doi.org/10.1099/mic.0.000155 